\title{
Prevalence and Correlates of Psychological Sufferings among Bangladeshi University Students
}

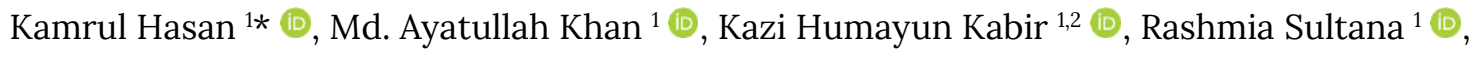 \\ Sardar Al Imran ${ }^{1}{ }^{\circ}$, Sanju Karmokar ${ }^{1}$ 다
}

${ }^{1}$ Development Studies Discipline, Khulna University, Khulna-9208, BANGLADESH

${ }^{2}$ The University of Hong Kong, Pok Fu Lam, HONG KONG

*Corresponding Author: shuvohasan1423@gmail.com

Citation: Hasan K, Khan MA, Kabir KH, Sultana R, Imran SA, Karmokar S. Prevalence and Correlates of Psychological Sufferings among Bangladeshi University Students. Journal of Contemporary Studies in Epidemiology and Public Health. 2020;1(2):ep20007. https://doi.org/10.30935/jconseph/8493

\begin{abstract}
Objectives: The intensity of psychological sufferings are noticeable among emerging university students which are linked with socio-demographic status and lifestyle conditions. The aim of this research was to determine the prevalence and correlates of depression, anxiety, and stress among university students in Bangladesh.

Materials and Methods: A cross-sectional study was performed among 450 Khulna University students in Bangladesh. Data were collected through an offline self-reported including socio-demographic and behavioral factors, and the 21-item Depression, Anxiety and Stress Scale (DASS-21). Ordered logit model was used to determine relative drivers of depression, anxiety, and stress.

Results: The prevalence of moderate to the extremely severe levels of depression, anxiety, and stress was $49.8 \%$, $54.4 \%$ and $37.7 \%$, respectively. The likelihood of psychological sufferings (depression, anxiety and stress) among participants has been mostly derived by being female, lower and middle class economic condition of the family, being engaged, poor academic performances, sleeping disturbances and $>=5$ hours internet use per day.

Conclusion: University level students are experienced a high amount of depression, anxiety and stress, with detrimental impact on their health, development, education and standard of living. The regularly scheduled work of the respective authorities should include counseling and sufficient assistance with awareness programme for the students. Besides, the students should be motivated to crave support in response to the psychological sufferings.

Keywords: drivers, psychological sufferings, university students, Bangladesh

Received: 28 Jun. $2020 \bullet$ Accepted: 29 Jul. 2020
\end{abstract}

\section{INTRODUCTION}

The years of university are identified as a period of transformation, sometimes stressful situations for life, immense educational pressure, detachment from parental care, self-decision making, sharing of living spaces with random individuals, the formation of new societies, balanced social responsibilities toward universities and other obligations of life [1-8]. In order to the advancement of a self-reliant personal life, majority of the undergraduate students are therefore passed through a series of psychological and psycho-social adjustments [1,7-9]. Hence, common psychological problems including depression, anxiety and stress are present among emerging university students and the extent and frequency of such stimuli and provisional occurrences seem to increase $[1-7,10]$.

Previous studies have shown the prevalence of psychological sufferings of some kind among the university level students in the past year. Prevalence of moderate to extremely severe levels of depression, anxiety and stress has been reported as to be $60.8 \%, 73 \%$ and $62.4 \%$ globally, respectively $[2-7,10]$. Depression, anxiety and stress have been found to be as severe in Bangladesh as $54.3 \%, 64.8 \%$, and $59.0 \%$, respectively $[1,9,11]$.

Previous studies have also outlined many relative drivers that lead to rising stress, anxiety and depression among university level students - including age particularly older age $[7,9,10]$; gender where male susceptibility in $[4,8]$, and female susceptibility in $[2,7,10,12]$; permanent residency specially susceptibility from rural area $[2,10]$; economic condition of family specially susceptibility for middle and lower class family $[1,2,7,10]$; relationship status where susceptibility for engaged in [1], susceptibility for unmarried in [7]; poor academic performance; lack of physical exercise; sleep disturbances; problematic internet usage and substances usage $[1,3,11,13-16]$. In addition, the predictor of the psychological sufferings among the students also included the pressure exerted by family and peers, high demands from family, future concerns, loneliness, psychological toxicity, academic 
pressure, high volume of work, academic curriculum, and repetitive test schedules $[4,5,17-19]$.

Research have indicated that a wide range of students day-to-day activities and health-being, including physiological health and growth, academic excellence (the academic year percentage, grade point average) and well-being are adversely influenced by psychiatric illnesses. It has also a worsening consequence over their own families, institutions and well-being of everyone else $[2,5,20]$. Besides, the most important predictors of suicide in Asian countries including Bangladesh were found to be psychological sufferings. Evidences revealed that nearly $90 \%$ of the accusers of suicide usually have at least one psychiatric illness [21-24]. Therefore, psychological sufferings among university level students in Bangladesh is a frequently reported area of research $[21,24]$. Besides, the increased levels of psychological sufferings among university level students in Bangladesh emphasize the requisite for future studies among this population. Existing research in Bangladesh have considered participants only from public university [1] or medical college $[9,25,26]$. Identifying the prevalence and correlates of psychological sufferings among Bangladeshi university students would instruct respective authorities in policy formulation aiming to combat this serious public health concern. Thus, the goal of this research was to determine the prevalence and correlates of psychological sufferings among Khulna University students in Bangladesh.

\section{MATERIALS AND METHODS}

\section{Study Design and Location}

The present cross-sectional study was conducted among the students who are enrolled in the undergraduate programme of Khulna University (Khulna-9208, Bangladesh). Khulna University is a public university which is situated at South-western region of Bangladesh Currently, there are 8 schools, 1 institute, 29 disciplines, and 6,965 students in the university [27].

\section{Data Collection}

From January 21, 2020 to February 11, 2020, data have been gathered. The responses were extracted using an offline self-reported survey questionnaire and DASS-21, using a convenience sampling technique. Questionnaires were circulated to students who live in student dormitories. The questionnaire was split into two parts. First portion included basic socio-demographic and lifestyle related information and in the second portion, 21-item multiple choice questionnaire, Depression Anxiety and Stress Scales (DASS-21) was afforded to examine the depression, anxiety and stress rates. The data enumerator provided support to fill the questionnaire and actively participated, wherever if required, through face to face interviews. DASS 21-point questionnaire, widely accepted and verified selfreporting survey tool for predicting the psychological depression, anxiety and stress [28]. It has been already used among the university level students of Bangladesh [1,9]. This scale consists of 21 items which encompasses scores on three subscales: depression (seven items), anxiety (seven items) and stress (seven items), inside a four-point Likert scale and range from never (0) to always (3). The DASS-21 has already become a well-established instrument for non-clinical studies with reasonably good psychometric properties $[5,15]$.

\section{Study Population}

A total of 450 participants from Khulna University were surveyed by following the inclusion and exclusion criteria.

\section{Inclusion criteria}

All students enrolled in an undergraduate programme who live in student dormitories were included in this study.

\section{Exclusion criteria}

Students suffering from diseases and medical problems and enrolled in a masters or equivalent programme were excluded from this study.

\section{Data Analysis}

Depending on the descriptive and inferential statistics, the data were processed, analyzed and interpreted. After the data were collected, edited and coded, data was processed and analyzed by using Statistical Package on Social Science (SPSS) 20.0 and STATA 13.0 Windows version. General characteristics of the participants were analyzed by means of descriptive statistics. Inferential statistics used an empirical model to determine the relative factors of psychological sufferings among the participants. By considering p-value $<0.05$ as statistical significance, the analysis was conducted.

\section{Empirical Model}

\section{Ordered logit model}

Depression, anxiety and stress are characterized at a five-point scale and are therefore categorized in ordered nature. For maintaining the ordered outcome, ordered logit regression model is one of the best statistical model that is used as an empirical model for analysis in this study [29].

\section{Explanatory variables}

In consideration of the reasonable relation with depression, anxiety and stress among university level students, a total of ten variables were listed as explanatory variables for regression analysis. The explanatory variables are considered based on a detailed literature analysis on relevant research $[1,7,10,14,30,31]$. All the explanatory variables are categorical, and their categories are listed with their identification code for categories in Table 1 .

\section{Ethical Considerations}

Study protocol were approved by an Independent Review Committee and have therefore been performed in accordance with the ethical standards of 2013 Declaration of Helsinki. Informed consent was taken from the participants.

\section{RESULTS}

\section{General Characteristics of the Participants}

The socio-demographic and behavioral factors are presented in Table 1. More than half of the participants were aged between 17 to 20 years $(58.2 \%)$, being male (62.9\%), being urban residence $(62.9 \%)$ and from middle class family (56.9\%). Relationship status of the sampled participants demonstrated that about $45 \%$ of the participants were engaged. More than one-third of the sampled participants had average (39.8\%) and poor (38.7\%) academic performance, respectively. 
Table 1. General characteristics of the participants $(n=450)$

\begin{tabular}{|c|c|c|}
\hline Characteristics & Frequency & Percentage \\
\hline \multicolumn{3}{|l|}{ Age group (years) } \\
\hline 18 to 20 & 262 & 58.2 \\
\hline$\geq 21$ & 188 & 41.8 \\
\hline \multicolumn{3}{|l|}{ Gender } \\
\hline Female & 167 & 37.1 \\
\hline Male & 283 & 62.9 \\
\hline \multicolumn{3}{|c|}{ Permanent residency } \\
\hline Urban & 283 & 62.9 \\
\hline Rural & 167 & 37.1 \\
\hline \multicolumn{3}{|c|}{ Economic condition of family } \\
\hline Upper & 103 & 22.9 \\
\hline Middle & 256 & 56.9 \\
\hline Lower & 91 & 20.2 \\
\hline \multicolumn{3}{|l|}{ Relationship status } \\
\hline Single & 250 & 55.6 \\
\hline Engaged & 200 & 44.4 \\
\hline \multicolumn{3}{|c|}{ Academic Performance } \\
\hline Excellent & 97 & 21.6 \\
\hline Average & 179 & 39.8 \\
\hline Poor & 174 & 38.7 \\
\hline \multicolumn{3}{|c|}{ Physical exercise engagement } \\
\hline Yes & 281 & 62.4 \\
\hline No & 169 & 37.6 \\
\hline \multicolumn{3}{|l|}{ Sleeping satisfaction } \\
\hline Yes & 177 & 39.3 \\
\hline No & 273 & 60.7 \\
\hline \multicolumn{3}{|c|}{ Daily internet use (hours) } \\
\hline $0-4$ & 203 & 45.1 \\
\hline$\geq 5$ & 247 & 54.9 \\
\hline \multicolumn{3}{|l|}{ Substance use } \\
\hline Yes & 218 & 48.4 \\
\hline No & 232 & 51.6 \\
\hline
\end{tabular}

Table 2. Prevalence of different psychological sufferings among participants

\begin{tabular}{cccc}
\hline Unit & Depression & Anxiety & Stress \\
\hline Normal & $31.8 \%$ & $28.4 \%$ & $40.9 \%$ \\
\hline Mild & $18.4 \%$ & $17.1 \%$ & $21.3 \%$ \\
\hline Moderate & $21.8 \%$ & $16.2 \%$ & $16.4 \%$ \\
\hline Severe & $17.6 \%$ & $21.1 \%$ & $12.9 \%$ \\
\hline Extremely severe & $10.4 \%$ & $17.1 \%$ & $8.4 \%$ \\
\hline
\end{tabular}

Lifestyle characteristics include engagement in physical exercise, satisfaction with sleep, daily internet use (hours) and substance use. Engagement in physical exercise noted that approximately $62 \%$ of participants were engaged in physical exercise for at least 20 minutes per day (e.g. walking, sports, games, cycling, swimming, or any other relevant activity). More than half of the participants were not satisfied with their sleeping hours (60.7\%) and were used internet $\geq 5$ hours (54.9\%) per day. There were no differences found in the use of substances among the participants.

Prevalence and Correlates of Psychological Sufferings among the Participants

The prevalence of psychological sufferings among university level students is being included in Table 2. The overall prevalence rates of moderate to extremely severe levels of depression, anxiety and stress were $49.8 \%, 54.4 \%$ and $37.7 \%$, respectively.

The ordered logit model had been used to determine the relative drivers of different psychological sufferings (depression, anxiety and
Table 3. Estimated result of the ordered logit model on relative drivers of different psychological sufferings among participants

\begin{tabular}{|c|c|c|c|}
\hline \multirow[t]{2}{*}{ Covariates } & \multicolumn{3}{|c|}{$\begin{array}{l}\text { Psychological Sufferings Adjusted Odds } \\
\text { Ratio }[95 \% \mathrm{CI}]\end{array}$} \\
\hline & $\begin{array}{l}\text { Depression } \\
\end{array}$ & Anxiety & Stress \\
\hline \multicolumn{4}{|l|}{ Age group (years) } \\
\hline \multicolumn{4}{|c|}{17 to 20 (Ref.) } \\
\hline$\geq 21$ & $\begin{array}{c}1.23 \\
{[0.85-1.78]}\end{array}$ & $\begin{array}{c}1.11 \\
{[0.78-1.59]}\end{array}$ & $\begin{array}{c}2.13 \\
{[1.44-3.15]^{* *}}\end{array}$ \\
\hline \multicolumn{4}{|l|}{ Gender } \\
\hline \multicolumn{4}{|c|}{ Female (Ref.) } \\
\hline Male & $\begin{array}{c}0.33 \\
{[0.21-0.50]^{* *}}\end{array}$ & $\begin{array}{c}0.46 \\
{[0.31-0.69]^{* *}}\end{array}$ & $\begin{array}{c}0.25 \\
{[0.16-0.39]^{* * *}}\end{array}$ \\
\hline \multicolumn{4}{|c|}{ Permanent residency } \\
\hline \multicolumn{4}{|c|}{ Urban (Ref.) } \\
\hline Rural & $\begin{array}{c}0.73 \\
{[0.47-1.12]} \\
\end{array}$ & $\begin{array}{c}0.78 \\
{[0.51-1.18]} \\
\end{array}$ & $\begin{array}{c}0.66 \\
{[0.42-1.03]} \\
\end{array}$ \\
\hline \multicolumn{4}{|c|}{ Economic condition of family } \\
\hline \multicolumn{4}{|c|}{ Upper (Ref.) } \\
\hline Middle & $\begin{array}{c}1.77 \\
{[1.14-2.76]^{*}} \\
\end{array}$ & $\begin{array}{c}2.03 \\
{[1.32-3.14]^{* *}} \\
\end{array}$ & $\begin{array}{c}2.14 \\
{[1.34-3.43]^{* *}} \\
\end{array}$ \\
\hline Lower & $\begin{array}{c}3.78 \\
{[2.04-6.99]^{* *}}\end{array}$ & $\begin{array}{c}2.92 \\
{[1.61-5.31]^{* *}} \\
\end{array}$ & $\begin{array}{c}4.39 \\
{[2.30-8.38]^{* *}}\end{array}$ \\
\hline \multicolumn{4}{|l|}{ Relationship status } \\
\hline \multicolumn{4}{|c|}{ Single (Ref.) } \\
\hline Engaged & $\begin{array}{c}3.03 \\
{[2.09-4.39]^{* *}} \\
\end{array}$ & $\begin{array}{c}1.90 \\
{[1.34-2.70]^{* *}} \\
\end{array}$ & $\begin{array}{c}4.72 \\
{[3.18-7.01]^{* *}}\end{array}$ \\
\hline \multicolumn{4}{|c|}{ Academic Performance } \\
\hline \multicolumn{4}{|c|}{ Excellent (Ref.) } \\
\hline Average & $\begin{array}{c}2.27 \\
{[1.39-3.72]^{* *}}\end{array}$ & $\begin{array}{c}1.01 \\
{[0.63-1.62]} \\
\end{array}$ & $\begin{array}{c}1.49 \\
{[0.89-2.48]}\end{array}$ \\
\hline Poor & $\begin{array}{c}5.29 \\
{[3.54-9.91]^{* *}}\end{array}$ & $\begin{array}{c}1.73 \\
{[1.08-2.79]^{*}}\end{array}$ & $\begin{array}{c}2.48 \\
{[1.48-4.16]^{\text {** }}}\end{array}$ \\
\hline \multicolumn{4}{|c|}{ Physical exercise engagement } \\
\hline $\begin{array}{c}\text { No } \\
\text { Sleeping satisfacti }\end{array}$ & $\begin{array}{c}2.30 \\
{[1.59-3.34]^{* *}}\end{array}$ & $\begin{array}{c}1.35 \\
{[0.95-1.92]} \\
\end{array}$ & $\begin{array}{c}3.07 \\
{[2.10-4.51]^{* *}}\end{array}$ \\
\hline \multicolumn{4}{|c|}{ Sleeping satisfaction } \\
\hline No & $\begin{array}{c}2.12 \\
{[1.45-3.09]^{* *}}\end{array}$ & $\begin{array}{c}1.69 \\
{[1.18-2.43]^{* *}}\end{array}$ & $\begin{array}{c}2.25 \\
{[1.51-3.34]^{* * *}}\end{array}$ \\
\hline \multicolumn{4}{|c|}{ Daily internet use (hours) } \\
\hline$\geq 5$ & $\begin{array}{c}2.77 \\
{[1.91-4.01]^{* *}} \\
\end{array}$ & $\begin{array}{c}2.06 \\
{[1.44-2.94]^{* *}} \\
\end{array}$ & $\begin{array}{c}3.41 \\
{[2.31-5.04]^{* *}} \\
\end{array}$ \\
\hline \multicolumn{4}{|l|}{ Substance use } \\
\hline \multicolumn{4}{|c|}{ Yes (Ref.) } \\
\hline No & $\begin{array}{c}0.93 \\
{[0.62-1.39]} \\
\end{array}$ & $\begin{array}{c}0.99 \\
{[0.67-1.47]} \\
\end{array}$ & $\begin{array}{c}0.71 \\
{[0.46-1.10]} \\
\end{array}$ \\
\hline
\end{tabular}

CI: Confidence Interval. Ref.: Reference. ${ }^{*}$-value $<0.05 ;{ }^{* *} p$-value $<0.01$

stress) among university level students. Estimated result of the ordered logit model on relative drivers of different psychological sufferings (depression, anxiety and stress) among participants are presented in Table 3. The likelihood of psychological sufferings (depression, anxiety and stress) among participants has been mostly derived by being female, lower and middle class economic condition of the family, being engaged, poor academic performances, without sleeping satisfaction and $\geq 5$ hours internet use per day.

Participants from middle and lower class family were more likely to suffer from depression, anxiety and stress than those from upper class family. Participants, being engaged were 3.03, 1.90 and 4.72 times more likely to be suffered from depression, anxiety and stress than those being single, respectively. Poor academic performance of the 
participants was about 5.29, 1.73 and 2.48 times more likely to develop all the psychological sufferings than those have excellent academic performance, respectively. Participants without sleeping satisfaction were 2.12, 1.69 and 2.25 times more likely to suffer from depression, anxiety and stress than their counterparts with sleeping satisfaction, respectively. Suffering from depression, anxiety and stress among participants using internet $\geq 5$ hours daily were $2.77,2.06$ and 3.41 times more likely than their counterparts using internet 0-4 hours daily, respectively. In contrast, Male participants were $67 \%, 54 \%$ and $75 \%$ less likely to suffer from depression, anxiety and stress than their female counterparts, respectively.

Moreover, participants aged $\geq 21$ years were 2.13 times more likely to suffer from stress than those aged between 18-20 years. Participants with average academic performance were 2.27 times more likely to be depressed than those with excellent academic performance. Consequently, participants without physical exercise engagement were 2.30 and 3.07 times more likely to suffer from depression and stress than those engage with physical exercise.

\section{DISCUSSION}

This study was conducted in Bangladesh to determine psychological sufferings and their relative drivers among university level students. The result of this study showed that the overall prevalence rates of moderate to extremely severe levels of depression, anxiety and stress were $49.8 \%, 54.4 \%$ and $37.7 \%$, respectively. This study findings are quiet similar relative to the previous study among northern Bangladeshi graduate students (49.6\% depression, $53.2 \%$ anxiety, and $26.4 \%$ stress) except stress [11]. Two research conducted among Bangladeshi university and medical students found $52.2 \%$ to $54.3 \%$ depression, $58.1 \%$ to $64.8 \%$ anxiety, and $24.9 \%$ to $59.0 \%$ stress $[1,9]$.

The prevalence of depression using DASS scale was higher in this study compare than some Asian countries like 32.0\% in India [6], 29.9\% in Nepal [32], $1.9 \%$ to $48.4 \%$ [4,5,33], 37.2\% in Malaysia [10], 28.5\% in Jordan [12] and 30 to $43 \%$ in Saudi Arabia [3]. The prevalence of anxiety in this study using DASS scale was found similar in some Asian countries including 54.5\% in Pakistan [33] and 47\% to 63\% in Saudi Arabia [3], but lower than some Asian countries including 50.3\% to $73.4 \%$ in Pakistan [4,5] and 63\% in Malaysia [10], and higher than some Asian countries including 28.5\% in Jordan [12], 40.1\% in India [6] and $41.1 \%$ in Nepal [32]. The prevalence of stress in this study using DASS scale was found similar in an Asian country including 30 to $41 \%$ in Saudi Arabia [3], but higher than some Asian countries including 3.6\% to 11.8\% in Pakistan [5,33], 23.7\% in Malaysia [10], 22.6\% in Jordan [12] and $27 \%$ in Nepal [32], and but lower than some Asian countries including 47.6\% in Pakistan [4] and 43.8\% in India [6].

This research has shown that students in the older class have a higher stress level. This results are consistent with the study among university level students of Egypt, Malaysia and Bangladesh $[7,9,10]$. This may be because of expanding role and workload with the increase of years of seniority. Psychological sufferings have more impacted on female than their male counterparts in this study which are so close to $[2,7,10,12]$. This might tend to happen because of higher levels of selfexpectations, higher concerned about curriculum, confronted with fewer employment options and a perception of the inadequate technical skills and competences among female students. There has been no substantial association found between the DASS (Depression, Anxiety and Stress) and the participant's permanent residence by a previous study $[4,9]$. That findings are similar to this study. We found that the likelihood of psychological sufferings were higher among participants from middle and lower class family were more than those from upper class family. These findings are closed to the previous study by $[1,2,7,10]$. Being engaged in a relationship was identified to be a determinant of developing psychological sufferings among the participants in this study. A previous study found that being engaged in a relationship was responsible for developing anxiety and stress among Bangladeshi students [1]. Being unmarried was found to be a risk factors for developing stress, anxiety and depression among university students in Egypt [7]. However, being unmarried includes those who are single and have a relationship but not married in this study. This can be due to students living far away from their partners and/or due to their academic workloads, they have spent only little time with their partners. Poor academic performance was found to be a predictor for developing psychological sufferings among university level students in this study. Some studies have shown a strong link between the psychological sufferings and poor academic performance among university level students $[13,14]$.

In this study, lack of physical exercise was found to be a significant drivers for developing depression and stress among the participants. Several studies have reported that less physical exercise engagement have been contributed to the risk of psychological sufferings among university level students $[1,3]$. In order to achieve and sustain the individual's physiological balance, sleeping plays an integral role in personal quality of life. Sleep disruption lists as an indication for particular psychological suffering in Diagnostic and Statistical Manual of Mental Disorders (DSM-5) and correlations have been well documented between lower quality of sleep and signs of anxiety and depression [34]. In a previous study in Bangladesh, sleep disturbances were found to lead to the likelihood of depression and stress [1]. The present study also found that participants without sleeping satisfaction were more likely to develop psychological sufferings than their counterparts with sleeping satisfaction. More time spent on internet using each day was also noted as a significant relative driver of psychological sufferings in this study (i.e. $\geq 5$ hours/day). Problematic internet usage is correlated with the common psychological problems including depression, anxiety, stress, insomnia, loneliness, and lower self-esteem which is confirmed by this study in supporting the psychological literature $[1,11,15,16]$. Experiencing depression, anxiety, and stress signs could be linked with substances use [3]. Even though substance use is potentially a tool for combating symptoms of stress, anxiety and depression, at least to some extent. But our study found no significant relationship with substance use and psychological sufferings among the participants.

\section{LIMITATIONS}

The limitations of the study should be described. At first, the crosssectional design of this study is a common limitation. It is therefore difficult to determine the nature of impact and prevents us from deciding to make causal inferences regarding our results. A longitudinal research can show findings with greater accuracy. Secondly, a convenience sampling was used to collect data from only a university of Bangladesh which is also regarded as a major limitation of this study. Thus, the results do not represent the overall university students from 
Bangladesh. Thirdly, participants with diseases and medical problems and enrolled in a masters or equivalent programme were excluded from this study, that might be influenced the generalizability of the population. Longitudinal research with sufficiently strong and nationwide representative samples with the consideration of related drivers of depression, anxiety, and stress are therefore suggested.

\section{CONCLUSIONS}

A considerable number of Bangladeshi university students have reported psychological sufferings. The prevalence is higher with significantly associated drivers of depression, anxiety, and stress which includes being female, lower- and middle-class economic condition of the family, being engaged, poor academic performances, sleeping disturbances and $\geq 5$ hours internet use per day. However, psychological sufferings among students is a worldwide concern, and no society or community is exempt against the problems, whether it is a developing or developed country and traditional or modern world. The remedy ought to be cautious, respond quicker and to provide timely and sufficient assistance. Besides, the students should be motivated to crave support in response to the psychological sufferings.

\section{ACKNOWLEDGEMENT}

We would like to recognize the kind assistance of the participants during data collection of this study. We also appreciate all the personnel for supporting the completion of this study and its data collection.

\section{REFERENCES}

1. Mamun MA, Hossain MS, Griffiths MD. Mental health problems and associated predictors among Bangladeshi students. International Journal of Mental Health and Addiction. 2019:1-15. (doi: 10.1007/s11469-019-00144-8).

2. Bayram N, Bilgel N. The prevalence and socio-demographic correlations of depression, anxiety and stress among a group of university students. Social psychiatry and psychiatric epidemiology. 2008;43(8):667-72. (doi: 10.1007/s00127-008-0345-x).

3. Kulsoom B, Afsar NA. Stress, anxiety, and depression among medical students in a multiethnic setting. Neuropsychiatric disease and treatment. 2015;11:1713. (doi: 10.2147/NDT.S83577).

4. ul Haq MA, Dar IS, Aslam M, Mahmood QK. Psychometric study of depression, anxiety and stress among university students. Journal of Public Health. 2018;26(2):211-7. (doi: 10.1007/s10389-0170856-6)

5. Saeed H, Saleem Z, Ashraf M, Razzaq N, Akhtar K, Maryam A, et al. Determinants of anxiety and depression among university students of Lahore. International Journal of Mental Health and Addiction. 2018;16(5):1283-98. (doi: 10.1007/s11469-017-9859-3).
6. Taneja N, Sachdeva S, Dwivedi N. Assessment of depression, anxiety, and stress among medical students enrolled in a medical college of New Delhi, India. Indian Journal of Social Psychiatry 2018;34(2):157-62.

7. Wahed WYA, Hassan SK. Prevalence and associated factors of stress, anxiety and depression among medical Fayoum University students. Alexandria Journal of medicine. 2017;53(1):77-84. (doi: 10.1016/j.ajme.2016.01.005).

8. Demirbatir RE. Undergraduate music student's depression, anxiety and stress levels: A study from Turkey. Procedia-Social and Behavioral Sciences. 2012;46:2995-9. (doi: 10.1016/j.sbspro.2012.05.603).

9. Alim SAHM, Rabbani MG, Karim E, Mullick MSI, Al Mamun A, Khan MZR. Assessment of depression, anxiety and stress among first year MBBS students of a public medical college, Bangladesh. Bangladesh Journal of Psychiatry. 2015;29(1):23-9.

10. Shamsuddin K, Fadzil F, Ismail WSW, Shah SA, Omar K, Muhammad NA, et al. Correlates of depression, anxiety and stress among Malaysian university students. Asian journal of psychiatry. 2013;6(4):318-23. (doi: 10.1016/j.ajp.2013.01.014).

11. Mamun MA, Rafi MA, Al Mamun AS, Hasan MZ, Akter K, Hsan $\mathrm{K}$, et al. Prevalence and psychiatric risk factors of excessive internet use among northern Bangladeshi job-seeking graduate students: a pilot study. International Journal of Mental Health and Addiction. 2019:1-11. (doi: 10.1007/s11469-019-00066-5).

12. Hamaideh SH. Alexithymia among Jordanian university students: Its prevalence and correlates with depression, anxiety, stress, and demographics. Perspectives in psychiatric care. 2018;54(2):274-80. (doi: 10.1111/ppc.12234).

13. Mihăilescu A, Diaconescu L, Ciobanu A, Donisan T, Mihailescu C. The impact of anxiety and depression on academic performance in undergraduate medical students. European Psychiatry. 2016;33:S341-S2. (doi: 10.1016/j.eurpsy.2016.01.761).

14. Vitasari P, Wahab MNA, Othman A, Herawan T, Sinnadurai SK. The relationship between study anxiety and academic performance among engineering students. Procedia-Social and Behavioral Sciences. 2010;8:490-7. (doi: 10.1016/j.sbspro.2010.12.067).

15. Ostovar S, Allahyar N, Aminpoor H, Moafian F, Nor MBM, Griffiths MD. Internet addiction and its psychosocial risks (depression, anxiety, stress and loneliness) among Iranian adolescents and young adults: A structural equation model in a cross-sectional study. International Journal of Mental Health and Addiction. 2016;14(3):257-67. (doi: 10.1007/s11469-015-9628-0). 
16. Younes F, Halawi G, Jabbour H, El Osta N, Karam L, Hajj A, et al. Internet addiction and relationships with insomnia, anxiety, depression, stress and self-esteem in university students: A crosssectional designed study. PloS one. 2016;11(9):e0161126. (doi: 10.1371/journal.pone.0161126).

17. Al Mamun M, Griffiths MD. The association between Facebook addiction and depression: A pilot survey study among Bangladeshi students. Psychiatry research. 2019;271:628-33. (doi: 10.1016/j.psychres.2018.12.039).

18. Mayer FB, Santos IS, Silveira PS, Lopes MHI, de Souza ARND, Campos EP, et al. Factors associated to depression and anxiety in medical students: a multicenter study. BMC medical education. 2016;16(1):282. (doi: 10.1186/s12909-016-0791-1).

19. Silva RG, Figueiredo-Braga M. Evaluation of the relationships among happiness, stress, anxiety, and depression in pharmacy students. Currents in Pharmacy Teaching and Learning. 2018;10(7):903-10. (doi: 10.1016/j.cptl.2018.04.002).

20. Bruffaerts R, Mortier P, Kiekens G, Auerbach RP, Cuijpers P, Demyttenaere K, et al. Mental health problems in college freshmen: Prevalence and academic functioning. Journal of affective disorders. 2018;225:97-103. (doi: 10.1016/j.jad.2017.07.044).

21. Arafat SY, Al Mamun M. Repeated suicides in the University of Dhaka (November 2018): Strategies to identify risky individuals. Asian journal of psychiatry. 2019;39:84. (doi: 10.1016/j.ajp.2018.12.014)

22. Arafat SY. Suicide in Bangladesh: a mini review. Journal of Behavioral Health. 2017;6(1):66-9. (doi: 10.5455/jbh.20160904090206).

23. Arafat SY. Current challenges of suicide and future directions of management in Bangladesh: a systematic review. Global Psychiatry. 2018;1(ahead-of-print). (doi: 10.2478/gp-2019-0001).

24. Shah M, Ali M, Ahmed S, Arafat S. Demography and risk factors of suicide in Bangladesh: a six-month paper content analysis. Psychiatry journal. 2017;2017. (doi: 10.1155/2017/3047025).
25. Eva EO, Islam MZ, Mosaddek ASM, Rahman MF, Rozario RJ, Iftekhar AMH, et al. Prevalence of stress among medical students: a comparative study between public and private medical schools in Bangladesh. BMC research notes. 2015;8(1):327. (doi: 10.1186/s13104-015-1295-5).

26. Sultana N. Stress and depression among undergraduate medical students of Bangladesh. Bangladesh Journal of Medical Education. 2011;2(1):6-9.

27. University K. Khulna University - খুলনা বিশ্ববিদ্যালয় 2020 [cited 2020 February 27]. Available from: https://ku.ac.bd

28. Lovibond PF, Lovibond SH. The structure of negative emotional states: Comparison of the Depression Anxiety Stress Scales (DASS) with the Beck Depression and Anxiety Inventories. Behaviour research and therapy. 1995;33(3):335-43.

29. Nwakuya MT, Mmaduka O. Ordered Logistic Regression on the Mental Health of Undergraduate Students. International Journal of Probability and Statistics. 2019;8(1):14-8.

30. Othieno CJ, Okoth RO, Peltzer K, Pengpid S, Malla LO. Depression among university students in Kenya: Prevalence and sociodemographic correlates. Journal of affective disorders. 2014;165:120-5. (doi: 10.1016/j.jad.2014.04.070).

31. Hirshkowitz M, Whiton K, Albert SM, Alessi C, Bruni O, DonCarlos L, et al. National Sleep Foundation's updated sleep duration recommendations: final report. Sleep Health. 2015;1(4):233-43.

32. Kunwar D, Risal A, Koirala S. Study of depression, anxiety and stress among the medical students in two medical colleges of Nepal. Kathmandu Univ Med J. 2016;53(1):22-6.

33. Yusoff MSB, Rahim AFA, Baba AA, Ismail SB, Pa MNM. Prevalence and associated factors of stress, anxiety and depression among prospective medical students. Asian journal of psychiatry. 2013;6(2):128-33. (doi: 10.1016/j.ajp.2012.09.012).

34. Association AP. Diagnostic and statistical manual of mental disorders. Fifth ed. Arlington: American Psychiatric Publishing; 2013. 